REVISTA DE GESTÃO ESECRETARIADO

MANAGEMENT AND ADMINISTRATIVE

PROFESSIONAL REVIEW

ISSN: 2178-9010
Revista GeSec

São Paulo, SP, Brasil

v. 12 , n. 3, p. $64-88$

set./dez. 2021

DOI: http://dx.doi.org/10.7769/gesec.v12i2.1202

\title{
Informação prospectiva: estratégia de ação no comércio informal do vestuário feminino
}

\section{Prospective information: action strategy in the informal women's clothing business}

\author{
Mayara Santos Silva ${ }^{1}$ \\ César Ricardo Maia de Vasconcelos ${ }^{2}$
}

\section{Resumo}

A presente pesquisa dedicou-se à exploração de novos conhecimentos sobre a temática informação prospectiva: estratégia de ação no comércio informal do vestuário feminino. Conceituar a mulher no cenário da informalidade e a cultura da informação é indispensável, pois as mulheres estão representadas no setor informal em todo o mundo e muitas, por trabalhar por conta própria, necessitam estar bem atualizadas. $O$ objetivo de estudo é conhecer a influência que a informação prospectiva exerce sobre o mercado informal do vestuário feminino. Quanto a metodologia, foi realizada revisão da literatura. O estudo representa um paradigma construtivista e de investigação qualitativa, possuindo um caráter descritivo e exploratório e utilizando-se de entrevistas semiestruturadas para a coleta de dados, a qual totalizou trinta entrevistados. As entrevistas ocorreram por meio de gravador de áudio e contaram com posterior transcrição para tratamento e análise das categorias temáticas, sugeridas por Bardin (2011), com a ajuda do software "NVivo 11". Os resultados foram relacionados em quatro categorias: Informação prospectiva, Vestuário feminino, Comércio informal e Inteligência competitiva. Há também seis subcategorias: Moda e consumo, "Boca a boca" e redes sociais, Informação, Grau de satisfação, Processo de informação e Tomada de decisões. A análise dos resultados obtidos a partir do instrumento de pesquisa apresentou que os entrevistados consideram a informação prospectiva matéria-prima da Inteligência Competitiva, como estratégia de ação na tomada de decisão. Conclui-se, que a informação prospectiva é considerada uma estratégia de ação no mercado informal de vestuário feminino. Por último, esta pesquisa teve como limitações o fato de não ser uma pesquisa quantitativa, abrangência da amostra e a dificuldade de marcar o horário com o entrevistado. Sugere-se realizar o estudo em outras regiões e utilizar uma amostra maior, pois o setor da informalidade tem apresentado grande crescimento e pouco estudo.

Palavras-Chaves: Comércio Informal. Informação Prospectiva. Inteligência Competitiva. Vestuário feminino.

\footnotetext{
${ }^{1}$ Mestre em Administração.

${ }^{2}$ Doutor em Administração, Docente no Mestrado Profissional em Administração e no Programa de Pós-graduação em Administração da Universidade Potiguar (UnP).
} 


\begin{abstract}
The present research was dedicated to the exploration of new knowledge on the thematic prospective information: strategy of action in the informal commerce of the feminine clothing. Conceptualizing women in the context of informality and the culture of information is essential, as women are represented in the informal sector throughout the world and many, because they are self-employed, need to be well up-to-date. The objective of the study is to know the influence that prospective information has on the informal market for women's clothing. As for the methodology, a literature review was carried out. The study represents a constructivist and qualitative research paradigm, having a descriptive and exploratory character and using semistructured interviews for data collection, which totaled thirty respondents. The interviews took place by means of an audio recorder and were later transcribed for treatment and analysis of the thematic categories, suggested by Bardin (2011), with the help of the "NVivo 11" software. The results were listed in four categories: Prospective information, Women's clothing, Informal trade and Competitive intelligence. There are also six subcategories: Fashion and consumption, "Word of mouth" and social networks, Information, Degree of satisfaction, Information process and Decision making. The analysis of the results obtained from the research instrument showed that the interviewees considered the prospective information as raw material of Competitive Intelligence, as an action strategy in decision making. In conclusion, the prospective information is considered an action strategy in the informal women's clothing market. Finally, this research had as limitations the fact that it is not a quantitative survey, sample coverage and the difficulty of making an appointment with the interviewee. It is suggested to carry out the study in other regions and to use a larger sample, as the informality sector has shown great growth and little study.
\end{abstract}

Keywords: Informal Trade. Prospective Information. Competitive intelligence. Women's Clothing.

\title{
Introdução
}

As mudanças fazem parte do mundo, das pessoas e das organizações. $O$ desenvolvimento de empreendimentos relacionados ao vestuário feminino no mercado informal é um dos exemplos de tais atividades adotadas por pessoas que, por um motivo ou por outro, não tiveram oportunidades no mercado formal, ou mesmo, foram excluídos desse último.

O contexto da moda teve início depois da segunda metade do séc. XIV com a revolução do vestuário (Villerd \& Hardill, 2010). Segundo os autores, no final do séc. XIX, Paris era a capital global da arte e da moda e continua, até os dias de hoje, como centro econômico e cultural do vestuário, no qual os estilos, as modelos e as estrelas do jet set internacional se misturam, fazendo da capital francesa uma eterna cidade de luz e elegância. O que influência a moda é o comportamento contemporâneo, que persuade a sociedade a desejar que a mulher obedeça à hierarquia social (Phelan, 2002). 
A literatura pertinente ao assunto mostra o grande número de informações disponíveis, insumos de produtos e serviços diferenciados. Não obstante, mais importante do que ter acesso à informação é a organização estar atenta à análise dos dados de maneira que o gestor se sinta preparado para, através da boa informação e no momento certo, tomar a decisão adequada e assim viabilizar as mudanças necessárias (Levet, 2001). Com a globalização e o consequente aumento da competitividade, a necessidade de obtenção dessas informações se torna fator importante nas empresas que atuam em todo tipo de mercado (Drucker, 1988), seja ele formal ou informal, este último como objeto deste estudo.

Torna-se importante ter um olhar voltado para as oportunidades do futuro (Fuller, 2016), de forma a ajustar a administração para eventuais problemas. O autor completa que, assim como as organizações, os envolvidos com o comércio informal precisam de estratégias para alavancar as suas atividades de forma a se manterem ativos em seus negócios. Muitas decisões são baseadas em crenças relativas à probabilidade de eventos incertos.

Nesse contexto, Levet (2001) aduz que a prática da Inteligência Competitiva (IC) surge como modo de pensar e agir; um processo de coleta, análise e tratamento da informação, mesmo que intuitivamente pelo responsável da atividade, para uso antecipado frente aos concorrentes do segmento informal. Sumariando, o presente trabalho visa conhecer a influência que a informação prospectiva, matéria-prima da inteligência competitiva, exerce sobre o mercado informal do vestuário feminino.

Como justificativa, o mercado informal por ser de fácil acesso, o empreendedor individual ou o coletivo (a organização) precisa estar bem-informado para poder agir prospectivamente às rápidas mudanças causadas pela turbulência informacional.

Nessa perspectiva, o estudo expressa a força das informações formal e informal, com ênfase nesta última. Em geral, esse tipo de informação é utilizado de forma intensiva e recebe tratamento diferente das informações mais estruturadas, ou seja, das formais (Andriotti, Freitas, \& Muniz, 2008). Pode ser encontrada tanto em fontes de informações como em certas situações que não são necessariamente formalizadas. Ou seja, não se tem garantia de que seja algo sério: um contato pessoal com o indivíduo, uma intuição, uma observação, entre outros (Freitas \& Muniz, 2006).

Diante do exposto, este estudo retrata o cenário da mulher na informalidade, à medida que está representada no setor informal em todo mundo. Com base nesses fatos, manifestouse o interesse em buscar compreensão sobre as informações formais e informais, matéria-prima da IC, prática estratégica das atividades comerciais, no caso em estudo, do comércio informal 
do vestuário feminino, tendo em vista a propositura de se obter, o quanto antes, uma atividade formal.

\section{Referencial Teórico}

\section{1 Informação}

No mundo globalizado, é preciso estar bem-informado para garantir eficiência e eficácia na tomada de decisões. Nenhuma empresa pode fugir dos efeitos que impulsionam a economia e a revolução da informação (Porter \& Millar, 1985). Frente à tanta informação, torna-se maior a necessidade de fazer escolhas (Kestenbaum, 2008). Assim, Calazans (2012) aponta que a informação é considerada um dos mais importantes motivos organizacionais, por ser o alicerce de geração de conhecimento.

O uso da informação é condicionado pelas diferenças de personalidade, pela cultura da organização, ou seja, a informação é uma questão de interpretação subjetiva pelo indivíduo que a adquire e a usa (Kaye, 1995). Assim, faz-se importante saber escolher que tipo de informação é necessário para entender onde vai ser coletada, ou seja, é preciso um monitoramento. A informação formal é definida como de fácil acesso, podendo ser encontrada em situações registradas e formalizadas, por exemplo, em documentos, livros, bases de dados, websites, entre outros (Freitas \& Muniz, 2006).

Consta-se que as organizações passam por diferentes situações diariamente, estando expostas a grandes quantidades de informações. Nesse sentido, Andriotti, Freitas e Muniz (2008) demonstram que, muitas vezes, a informação localizada não corresponde àquilo que foi buscado, devido a fatores como profundidade, relevância e atualidade. Portanto, o conhecimento informal é uma abordagem pessoal durante as conversas ou discussões, quando são abordadas perguntas e respostas, e, muitas vezes, reforça o desempenho do grupo (Davison, Ou, \& Martinsons, 2013).

Nesse sentido, o estudo dá ênfase à informação informal, pelo fato de as pessoas poderem relacionar-se e, assim, compartilhar informações para contribuir com a organização.

\section{2 Informação prospectiva}

Na perspectiva de Schenatto, Polacinski, Abreu e Abreu (2011), a tentativa de antecipar o futuro há muito vem sendo praticada pelas organizações, no desígnio de conseguir tempo para

Revista Gestão e Secretariado (GeSec), São Paulo, SP, v. 12, n. 3, set./dez., 2021, p. 64-88. 
planejar-se e sobrelevar seus competidores, com isso, conquistando espaço no campo competitivo. Já na visão de Leavy (2007), a análise prospectiva é um campo que investiga as forças técnicas, científicas, econômicas e sociais que produzem mudanças no ambiente.

A partir dessa observação, antecipam-se diversas situações e é possível preparar-se para o futuro. Os estudos do futuro constituem um ramo da atividade intelectual relacionado com todos os setores da vida social, econômica e cultural de uma pessoa, grupo ou organização (Torres, 2015). A informação prospectiva é definida em informações disponíveis para um intérprete, antes que o adversário comece a execução de habilidades, e o controle prospectivo é ligado diretamente ao ser humano (Farrow, 2012). Existe, assim, uma relação entre indivíduo e meio ambiente que permite uma ação direcionada a objetivos, que seja atualizada constantemente e esteja à frente do tempo (Correia et al., 2011). Esse controle prospectivo, segundo Guston (2014), define a governança antecipativa, que possui uma capacidade ampla e motiva as atividades a desenvolverem capacidades de previsão, interação e engajamento. É nesse sentido que Rosen (2012) permite mudar o estado de um instante de acordo com as previsões do modelo relativas ao instante posterior. Esse modelo utilizado é um modelo preditivo, que serve para atrair o futuro para o presente, que, na verdade, funciona como um sistema antecipado.

Na concepção de Ding (2017), os modelos existentes têm por base uma perspectiva de retrospectiva, ou melhor, os usuários podem continuar usando um sistema de informações com falhas ocasionais porque esperam melhorias possíveis, uma vez que os meios pelos quais um sistema vivo é internamente guiado e controlado envolvem informações codificadas (Rosen, 2012). Nessa conjuntura, Satur, Paiva e Duarte (2017) evidenciam a questão da dificuldade de verificar a integridade da informação, que pode ter sido provocada intencionalmente por interesse de alguma parte envolvida. Isso é chamado, por eles, de imperfeição da informação. Ou seja, a busca deixa de ser pela informação íntegra e passa a ser pela informação satisfatória.

Os comerciantes informais preocupam-se constantemente com sua posição no mercado devido às mudanças frequentes que surgem. Percebe-se a necessidade de antecipar mudanças, reconhecer oportunidades e monitorar o fluxo de informações sobre outras empresas e atividades no mesmo campo (Melo \& Medeiros, 2007). Essa é considerada uma conduta proativa, tornando-se um diferencial para a organização. Destina-se ao comportamento sociável, criando um conjunto de proveitos para a cultura organizacional (Chang, 2015), em que avaliar a incerteza é uma atividade importante na elaboração de estratégias e na tomada de decisões (Tapinos \& Pyper, 2018). 
Muito se constrói sobre a percepção do futuro como ferramenta indispensável e relevante para os gestores que buscam tornar-se suas organizações ainda mais competitivas (Schenatto, Polacinski, Abreu, \& Abreu, 2011). Os autores completam que não é possível prever tudo; reflexões acerca de ameaças e oportunidades do decorrer são resistentes e direcionadas. A informação prospectiva, matéria-prima da Inteligência Competitiva, pode ser observada como estratégia fundamental apreciada pelos tomadores de decisões.

\subsection{Comércio informal}

O setor informal persistiu e se expandiu nas últimas décadas. Menezes e Dedecca (2014) relatam que, até a década de 1970, o setor informal era visto como composto de atividades e ocupações precárias, as quais ganhavam sentido pelo fraco desempenho da economia, incapaz de empregar um excedente de força de trabalho.

Chen (2001) traz algumas razões que podem explicar esse fato: a taxa e o padrão de crescimento, que inclui a intensidade de trabalho e a composição setorial do crescimento; reestruturação econômica ou crise econômica, incluindo privatização de empresas públicas e cortes nos gastos públicos, entre outros. Nesse entendimento, Antunes (2010) retrata que a informalidade se torna cada vez mais permanente, pois compreender seus modos de expressões e seus significados é, então, importante para que se consiga melhor clareza dos mecanismos que impulsionam o mundo do trabalho da informalidade.

No momento atual, esse setor está formado pela maioria dos trabalhadores do mundo. Seu crescimento se deu desde a década de 1980, por duas razões: a crise econômica global e o modo como a produção vem sendo estruturada pelo capital transnacional (Gallin, 2001). Assim, torna-se um fenômeno da vida em sociedade que, por muitas vezes, é mascarado ou percebido na prática da vida cotidiana (Alonso-Almeida, Bremser, \& Llach, 2015).

O crescimento dos chamados "trabalhadores independentes" em todo mundo cresceu ainda mais com o impacto causado pela pandemia. Um cenário que é visto como incerto (Prates $\&$ Barborsa, 2020). Apoiar os trabalhadores pobres na economia informal é um caminho vital para reduzir a pobreza e a desigualdade (Chen, 2012). Muitas vezes, é a necessidade de superar a finalidade global da visão lógica de que o preço mais baixo é o que leva os consumidores a obter bens e serviços na economia informal (Williams \& Martinez-Perez, 2014).

\subsubsection{Mulher no cenário da informalidade}

No trabalho por conta própria, a presença feminina é maior entre as não remuneradas e na produção agrícola para o consumo próprio, tem apresentado êxito o aumento da participação 
da mulher na atividade econômica (Leone \& Baltar, 2008). Sabe-se que não é de hoje que a mulher procura obter participação no mercado. Logo, está bem representada no setor informal em todo o mundo.

Para Chen (2001), a principal fonte de emprego para as mulheres, na maioria dos países em desenvolvimento, é o setor informal, no qual elas são trabalhadoras domiciliares ou ambulantes. Vale frisar que o papel da mulher na concepção da força de trabalho constituiu um novo contexto a ser levado em consideração entre o espaço produtivo e o familiar (Natividade, 2009). Nesse cenário, no nosso dia a dia conhecemos muitas pessoas que são boas em algum ramo, seja em vendas, costuras, pinturas, artesanatos, entre outros. De uma forma ou outra, vem progredindo a participação da mulher como empreendedora. Elas estão concentradas em certos segmentos dentro do setor informal e não deixam de ser afetadas pelas tendências atuais (Chen, 2001). O autor ainda completa que as produtoras autônomas encontram dificuldades em manter seu espaço de mercado ou negociar acesso a mercados emergentes. Notoriamente, há a entrada cada vez maior da mulher no mercado de trabalho. Não obstante, os lugares ocupados por elas ainda são de forte desigualdade.

As rápidas mudanças exigem que as pessoas fiquem atentas às informações para que, assim, possam obter um diferencial no mercado. No entanto, Hirata (2004) relata que hoje em dia prevalece o trabalho autônomo das mulheres, pelas ruas, de porta em porta, indo à casa das pessoas. A sacoleira é uma figura muito presente ainda hoje, tendo como exemplo bastante competitivo o comércio do vestuário feminino.

Nessa perspectiva, a sacoleira está presente na vida de grande parte das mulheres e é considerada por muitas uma forma de praticidade, um bom relacionamento e um atendimento fidelizado. Sabe-se que o consumo faz parte da vida das mulheres e quem se mantém na informalidade precisa ficar atento aos novos desafios.

No entendimento de Bauman (2001), em sua obra Modernidade líquida, vivemos em constantes mudanças e nada foi feito para durar, tudo é temporário. O autor só afirma o que acontece nos dias de hoje: pessoas estão acompanhando as constantes mudanças e descartam o que é "antigo". Por essa razão, para conquistar uma posição no mercado, agora, estabelece-se uma grande adversidade. Em questão dos avanços tecnológicos, os consumidores têm se tornado, a cada dia, mais exigentes (Potrich \& Ruppenthal, 2013).

\subsection{Inteligência competitiva}

A Inteligência Competitiva tem como propósito compreender melhor os clientes, os mediadores, os concorrentes, entre outros, e, posteriormente, criar oportunidades, prevendo 
mudanças na busca por vantagem competitiva sustentável (Wright \& Calof, 2006). Nessa perspectiva, Gatsoris (2012) prisma que a coleta de informações é a parte fundamental dessa ferramenta, pois define os padrões de sucesso ao transformá-los em inteligência. Acredita-se que ultrapassar os concorrentes é enfrentar desafios externos e internos, nos quais, internamente, as empresas enfrentam pressão; já no ambiente externo, enfrentam oportunidades e ameaças (Eidizadeh, Salehzadeh, \& Esfahani, 2017). Por conseguinte, os cenários estão cada vez mais competitivos, a prospecção como fonte de informação estratégica e definição de prioridades das organizações é uma necessidade, sobretudo para criação de serviços eficientes aplicados a unidades de Informação (Casimiro \& Araújo, 2020).

Em meio a tantas necessidades, nota-se que as empresas buscam alternativas para alcançar seus objetivos de forma correta, a fim de se manterem firmes no mercado. Dessa forma, a IC é vista como um componente emergente na atual economia do conhecimento, assim como um capital de valor estratégico.

Levet (2001) ressalta que a Inteligência Competitiva apresenta duas questões cruciais para o seu funcionamento. São elas: (a) cooperação, que corresponde à capacidade da performance empresarial de agir coletivamente de forma coordenada; e (b) produção de novos conhecimentos, que está relacionada com a técnica de produzir, interpretar e analisar o conhecimento de modo que se possa antecipar a mudança.

Em síntese, o autor considera que a Inteligência Competitiva é um instrumento que toda empresa precisa obter, pois ajuda na diminuição dos riscos e lhe proporciona mais chances de manter-se firme no mercado.

\section{Metodologia}

A metodologia desta pesquisa tem como destino a aplicação de procedimentos e técnicas que precisam ser observados para a composição do conhecimento, com o objetivo de comprovar sua utilidade e validade no âmbito da sociedade (Prodanov \& Freitas, 2013). Assim, a presente pesquisa, quanto à sua natureza, apresenta uma abordagem qualitativa de investigação, sendo interpretativa e naturalística (Creswell, 2014). Quanto aos objetivos, a pesquisa pode se classificar em exploratória e descritiva. Por esse motivo, a estratégia da coleta de dados foi executada por um roteiro de entrevista. Com base no que foi apresentado pela literatura estudada, foi elaborado o roteiro de pesquisa com oito perguntas.

A coleta de dados ocorreu durante os meses de julho e agosto de 2018, em que todas as entrevistas foram conduzidas tendo por base um roteiro, gravadas através do gravador de voz 
do celular (aparelho Iphone 6S) e transcritas para uma posterior análise de conteúdo. Por conseguinte, uma ferramenta fundamental para a coleta de dados verbais é a gravação eletrônica e a posterior transcrição. Foram transcritos 150 minutos de entrevistas.

Os dados procedentes desta pesquisa foram coletados por meio de entrevistas semiestruturadas que, segundo (Flick, 2009) têm interessado muitos pesquisadores e vêm sendo bastante utilizadas. Para o tratamento de dados, foi realizada a análise de conteúdo das informações originárias das entrevistas feitas com clientes atuais e potenciais. Na concepção de (Bardin, 2011, p. 41), a análise de conteúdo consiste na "técnica de apurar descrições de conteúdo muito aproximativas, subjetivas, para pôr em evidência com objetividade a natureza e as forças relativas dos estímulos a que o sujeito é submetido".

Logo, os dados foram analisados através do software $\mathrm{NVivo}{ }^{\circledR}$, conforme procedimentos de (Lima \& Manini, 2017), o qual permite ao usuário uma abordagem teórica e metodológica usada na fundamentação no processo de análise, além do que, tem a finalidade de "busca, categorização, organização e registro da interpretação" dos dados coletados (Mozzato \& Grzybovski, 2011, p. 431).

O estudo foi realizado na cidade de Picuí (PB) e região. A pesquisa selecionou 30 participantes e todos eram do gênero feminino. Foi listado o nome das pessoas mais "próximas" do pesquisador que já considerados clientes. Assim, as entrevistas foram marcadas por meio do aplicativo WhatsApp ou pessoalmente e ocorreram da seguinte forma: marcados o dia e o horário, o encontro era na casa da entrevistada ou do entrevistador. Contudo, o software NVivo ${ }^{\circledR}$ segue a intenção de comparar o que foi extraído dos pesquisadores na entrevista, com o objetivo, com a categoria e com a leitura de suporte de estudo e questões abordadas. Observa-se na tabela 4 abaixo:

Tabela 1.

Grade de análise da pesquisa

\begin{tabular}{c|c} 
Categoria & Subcategorias \\
\hline \multirow{2}{*}{ Informação prospectiva } & Oportunidades futuras \\
\cline { 2 - 2 } Vestuário feminino & Capacidade de previsão \\
\hline \multirow{2}{*}{ Comércio informal } & Perfil das entrevistadas \\
\cline { 2 - 2 } & Moda e consumo \\
\cline { 2 - 2 } & "Boca a boca" e redes sociais \\
\cline { 2 - 2 } Inteligência competitiva & Informação \\
\cline { 2 - 2 } & Grau de satisfação \\
\cline { 2 - 2 } & Processo de informação \\
\hline
\end{tabular}

Fonte: Autores (2019) 


\section{Análise e discussão}

\subsection{Resultado ligado à sistematização de categorias}

Para o processo de codificação e categorização dos códigos, foi utilizado o software NVivo® versão 11 , em virtude deste proporcionar maior dinamicidade para análise dos elementos textuais, fornecendo subsídios para as funcionalidades de preparação, codificação e análise das informações coletadas nesta pesquisa.

A divisão em quatro categorias ("nós") principais ocorreu com base na análise de conteúdo firmada nos elementos de (Bardin, 2011): (1) Informação prospectiva; (2) Vestuário feminino; (3) Comércio informal e (4) Inteligência competitiva.

Após a criação dos "nós", as entrevistas transcritas foram inseridas no programa (denominadas de Respondente 01 a Respondente 30) e, em seguida, seus trechos foram selecionados e transportados para o "nó" e/ou "nós" relacionado(s).

Através das técnicas de consulta disponíveis no referido software, obtém-se resultados que contribuem para as discussões e conclusões finais, por exemplo: (a) frequência de palavras; (b) nuvem de palavras; (c) análise de cluster e (d) árvore de palavras. Dessa forma, cada um com sua finalidade específica, como são esclarecidos por Lage (2011) e Alves, Figueiredo Filho e Henrique (2015), quando revelam que, ao se tratar os dados com a técnica de frequência de palavras: (a) se alcança um resultado com perspectiva quantitativa, enquanto a utilização de nuvem de palavras (b) proporciona uma visualização de padrões semânticos, em que as palavras agrupadas são mais análogas (c). Já a árvore de palavras (d) promove uma melhor visualização dos dados, pois mostra a distribuição das palavras.

Todavia, antes de iniciar a avaliação dos 13 "nós" separadamente, para mostrar a semelhança das perguntas, foi importante fazer uma análise de cluster, pois designou-se as perguntas que estavam relacionadas entre si. Então, foi usada a métrica de similaridade da correlação de Pearson para melhor análise. 


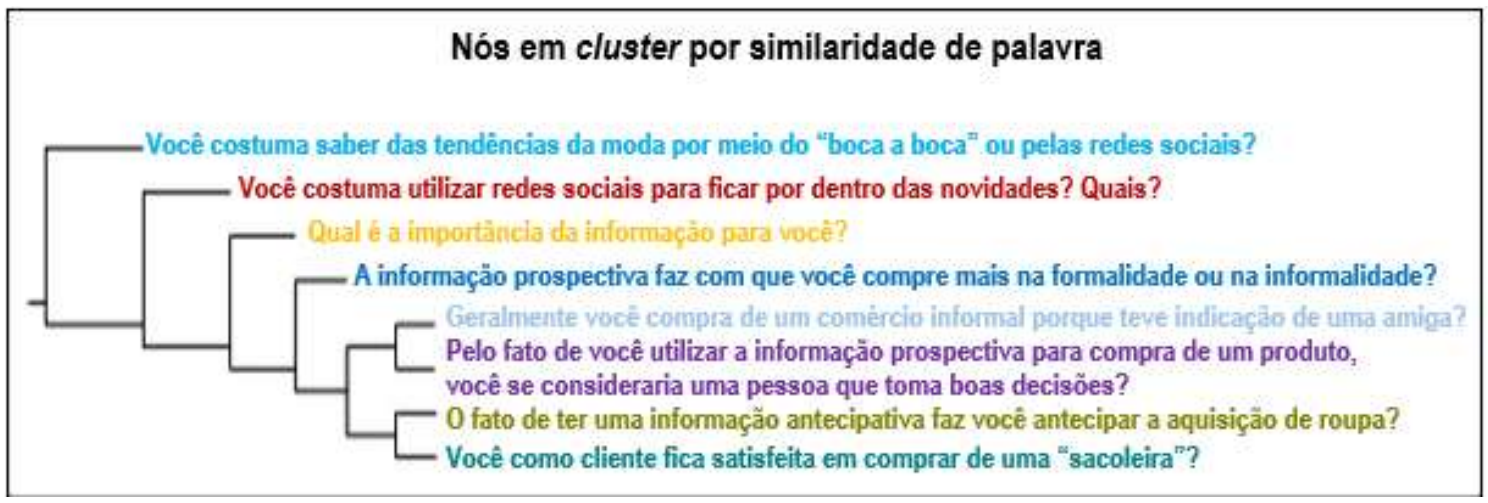

Figura 1. Análise de Cluster Fonte: NVivo (2011)

A Análise de Cluster é uma técnica exploratória para visualizar "nós" que partilham palavras semelhantes ou valores de atributos similares, ou que são codificados da mesma forma por nós. De acordo com Corrar, Paulo e Dias Filho (2009, p. 325), o propósito da Análise de Cluster é "reunir objetos, baseando-se nas características dos mesmos".

\subsection{Resultado ligado à categoria "informação prospectiva"}

Previamente, foi abordado o conceito de Informação Prospectiva para deixar as entrevistadas cientes do assunto tratado, com a seguinte definição: a informação prospectiva é "como uma simulação mental de acontecimentos futuros que promove ações positivas no presente com orientação para o futuro" (Coughlin; Lyons \& Ghetti, 2014, p. 1). Ao tratar desse ponto, observou-se que as respondentes não "conheciam" o significado de informação prospectiva, assim, isso foi esclarecido depois da exposição, dando início às entrevistas.

\subsubsection{Subcategoria oportunidades futuras}

Percebe-se que o ambiente muda de forma rápida e radical ao longo do recente passado evolutivo em que os modelos não poderão mais prever com segurança o próximo comportamento do ambiente a partir do comportamento atual. Ou seja, é preciso ficar atento ao tipo de informação e saber usá-la, pois a tecnologia não apresenta a garantia das respostas precisas, de modo que a informação e a tecnologia tendem a encontrar-se de forma independente (Prescott \& Miller, 2002). Desse modo, a análise dessa subcategoria tem por finalidade questionar os respondentes sobre: “Qual é a importância da informação para você?”. Obtiveram-se os seguintes entendimentos:

É um meio de despertar interesse para determinadas temáticas, seja na moda, seja na educação, na saúde, ela contribui em qualquer área. [Respondente (9)] 
Então, a informação seja em qual área é importante porque ela agrega valor, traz conhecimento, faz com que você interaja com o que está em sua volta. Você se torna uma pessoa dinâmica. [Respondente (20)]

De acordo com as conversações, a importância da informação é significativa na vida das entrevistadas, pelo motivo de ficarem sempre atualizadas e de receberem informações antecipadas, pois essa é uma forma de adiantar as compras e ficar por dentro das tendências.

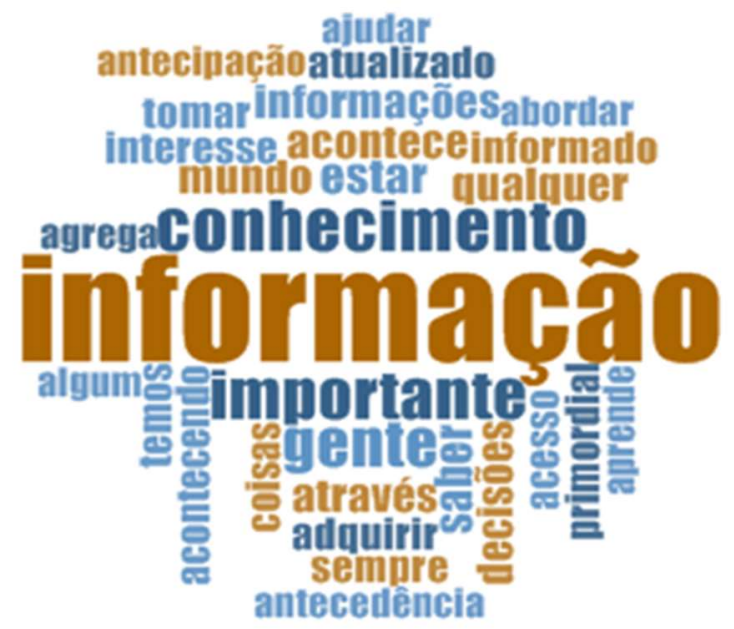

Figura 2. Nuvem de palavras da subcategoria "Oportunidades futuras" Fonte: Elaborada pelos autores via NVIVO® (2018)

Desse modo, após a inserção das fontes transcritas e a criação dos "nós", realizou-se uma consulta para identificar as palavras que surgiam com maior frequência durante o discurso dos entrevistados. Dentre elas, as três mais citadas na Figura 2 foram: "informação", "conhecimento" e "importante". Foram excluídas as palavras: "redor", "muito", "melhor" e "ficar", entre outras. A busca foi limitada pelas 30 palavras mais utilizadas e pelo comprimento mínimo de cinco palavras.

\subsubsection{Subcategoria: capacidade de previsão}

Foi perguntado às entrevistadas " $\mathrm{O}$ fato de ter uma informação prospectiva faz com que você antecipe a aquisição da roupa?" e elas assim se posicionaram:

Depende. Porque nem tudo que está na moda o meu perfil é. Eu costumo seguir a moda, se eu gostar eu posso adquirir aquele produto antecipadamente. Mas se for alguma tendência lá fora que não seja muito meu perfil, aí eu não vou adquirir. [Respondente (18)]

A informação ela faz com que eu adquira minha compra mais rapidamente. Porque se eu sei que aquilo ainda vai chegar, e eu estou tendo a oportunidade de ser a primeira a usar, pra mim isso define minha compra logo. [Respondente (25)] 
Durante o questionamento da pergunta abordada, observou-se que as respondentes, quando se trata de "moda", nem sempre aderem às tendências. Porém, ao entender o que é a informação prospectiva, mostraram o interesse de querer estar bem-informadas, pois, ao receberem tal informação, pensariam "não estou precisando, mas se eu gostar...", conforme evidenciam os depoimentos abaixo:

Só se fizer parte do meu estilo de vida, porque nem sempre as tendências da moda vão se adaptar àquilo que eu quero. Se me interessar, por mais que eu não tenha conhecimento ou que eu esteja tendo acesso, se pertencer ao meu gosto eu vou assimilar e se não, não fico. [Respondente (3)]

Após a inserção das fontes transcritas, verificou-se novamente a busca pelas palavras utilizadas com maior frequência no discurso das entrevistadas para essa subcategoria (nó):

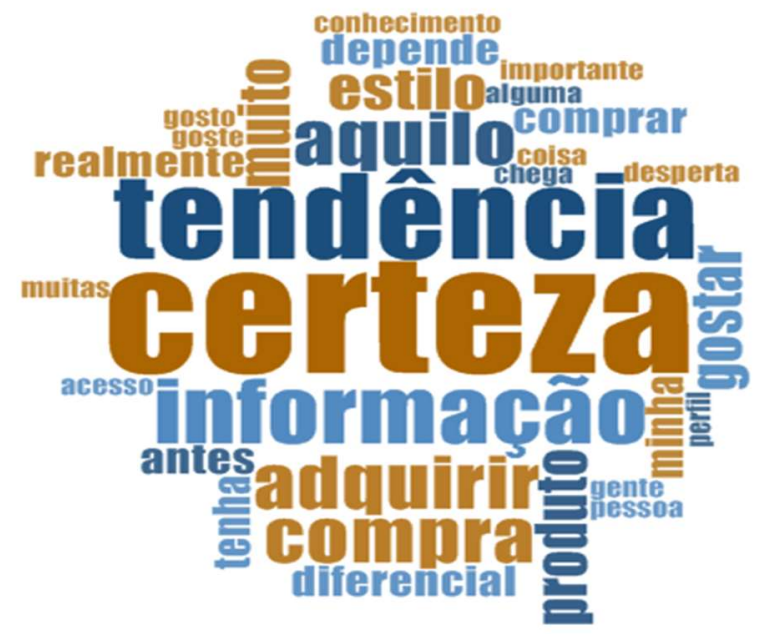

Figura 3. Nuvem de palavras da subcategoria Capacidade de previsão Fonte: Elaborada pelos autores via NVIVO ${ }^{\circledR}(2018)$

Assim, as cinco palavras mais citadas realçam como a informação prospectiva é significante na aquisição de roupa, pois é uma forma de ficar por dentro das novidades antes de outras pessoas. Como relata a respondente 11: eu vou pesar tipo: será que realmente vai ser tendência, será que essa tendência será útil para mim em outros momentos. Porque você tem a informação, mas nem tudo que eu recebo de informação antecipativa eu vou levar em consideração. Assim, serve para você ter uma base se vai adquirir ou não.

Portanto, a informação prospectiva é definida por Coughlin, Lyons e Ghetti (2014, p. 1) "como uma simulação mental de acontecimentos futuros que promove ações positivas no presente com orientação para o futuro", fazendo com que as pessoas tenham conhecimento antes das outras. 


\subsection{Resultado ligado à categoria "Vestuário feminino"}

Para obter as informações necessárias, foi necessário dividir essa categoria em duas subcategorias, "nós": perfil do cliente e moda e consumo.

\subsubsection{Subcategoria: perfil do cliente}

Por meio da subcategoria "perfil do cliente", os entrevistados foram questionados quanto ao seu gênero, faixa etária, renda e nível de escolaridade, a fim de conhecer o perfil dos tomadores de decisão do mercado informal do vestuário feminino acessível em Picuí/PB e região. Assim, predominou o gênero feminino (100\%), como foi abordado anteriormente, com clientes atuais e potenciais. Existe uma importância quanto à faixa etária, pois o vestuário feminino requer entender sua clientela para que as suas necessidades sejam atendidas. Dessa forma, a maioria das respondentes tem de 18 a 27 anos (80\%), já 20\% se encontram na faixa de 38 a 51 anos. Quanto à renda, dentre as respondentes, 50\% apresentaram renda de $\mathrm{R} \$ 1.100 \mathrm{a}$ $\mathrm{R} \$ 3.500,00$, em seguida, 33,33\% tem renda de $\mathrm{R} \$ 200,00$ a $\mathrm{R} \$ 1.000,00$ e, por último, $16,67 \%$ recebem de $\mathrm{R} \$ 3.600$ a $\mathrm{R} \$ 9.000,00$. Com relação ao nível de escolaridade, a maior parte do grupo de entrevistados $(46,67 \%)$ possui especialização, $30 \%$ têm nível médio, $16,67 \%$ têm graduação e 6,67\% têm nível fundamental.

\subsubsection{Subcategoria: moda e consumo}

Sabe-se que se manter atenta às novidades faz parte do dia a dia da mulher. A internet, nesse caso, é um meio bastante usado nos últimos anos, pela sua praticidade e custos acessíveis. Para fins desse "nó", fez-se o seguinte questionamento: "A informação prospectiva faz com que você compre mais na formalidade ou na informalidade?". As respostas foram as seguintes:

$\mathrm{Na}$ informalidade, pois é onde as publicações são mais fáceis de encontrar nas redes sociais. [Respondente (2)]

Nesse caso depende. Às vezes eu vou à sacoleira que está mais próxima, porém eu gosto de andar pesquisando. [Respondente (8)]

Às vezes você chega em uma loja e ela vai ter uma coleção toda, e normalmente ela vai querer vender aquilo ali. Já quando você vai para o mercado informal, você acaba adquirindo mais peças, porque o informal acaba sendo uma pessoa mais conhecida e próxima a você, que você passa confiança. Aí é mais fácil de você adquirir a peça. Diferente da loja, que a pessoa só vai querer vender. [Respondente (11)]

Observa-se que, para as respondentes, o mercado informal facilita o momento de compra, por conta da internet ou da "boca a boca", hoje muito comuns. Assim, durante as 
entrevistas, percebeu-se que sair para comprar, devido à correria do dia a dia, não é algo que esteja no primeiro plano delas. Espera-se olhar as redes sociais e resolver por meio dela mesmo como pode ser feita a compra. No momento em que a pessoa sai do informal e vai até a cliente, cria-se um laço de confiança que pode ser fidelizado naquele momento. No entanto, para esse "nó", foram identificadas 30 palavras-chave que foram utilizadas com maior frequência pelas entrevistadas.

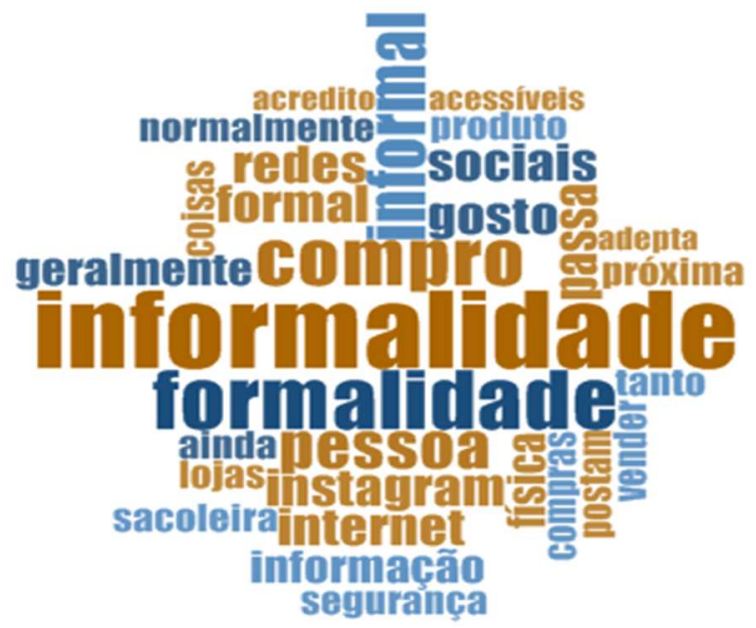

Figura 4. Nuvem de palavras da subcategoria "Moda e consumo"

Fonte: Elaborada pelos autores via NVIVO ${ }^{\circledR}(2018)$

\subsection{Resultado ligado à categoria comércio informal}

$\mathrm{Na}$ análise da categoria "Comércio informal" para analisá-la, foram consideradas três subcategorias: "Boca a boca e redes sociais", "Informação" e "Grau de satisfação".

\subsubsection{Subcategoria: "boca a boca" e redes sociais}

A análise de “'Boca a boca' e redes sociais” visa compreender a percepção dos entrevistados com relação à forma como procuram ficar por dentro das novidades sobre as tendências de moda. Ao se fazer o questionamento: "Você costuma saber das tendências da moda através da 'boca a boca' ou das redes sociais?", obteve-se os seguintes entendimentos:

Eu acho que meio termo. Algumas aquisições são pelas redes sociais, mas sempre tem alguém que chega e dá um toque que determinado local tem isso que você poderia gostar. [Respondente (9)]

Boca a boca, sou conectada nas redes sociais, mas muitas vezes você tem uma amiga que vai comprar uma peça e te diz que isso aqui vai ser muito usado, daí você vai nas redes sociais e confirma. Eu acho que as redes sociais é o posterior. [Respondente (11)] 
Redes sociais. Porque sigo as blogueiras que postam as tendências e fico por dentro. [Respondente (18)]

Infere-se que as entrevistadas buscam a informação através das redes sociais, porém a indicação da "boca a boca" também é um meio bastante utilizado entre elas. Desse modo, a facilidade que temos hoje com as redes sociais, as quais permitem que as pessoas estendam a "boca a boca" ainda mais, torna-se um incentivo para o consumo. Ao mesmo tempo, "podem ser utilizadas como espaço para formação de opinião, bem como para divulgação de ideias, fatos e informações relevantes" (Bezerra, 2016). De fato, hoje em dia prevalece o trabalho autônomo das mulheres, pelas ruas, de porta em porta, indo à casa das pessoas.

\subsubsection{Subcategoria: informação}

Para apreciação desse "nó", fez-se o seguinte questionamento: "Geralmente você compra de um comércio informal porque teve indicação de uma amiga?", obtendo-se os seguintes entendimentos:

Também. Porque a questão do conhecimento que alguém comprou um produto de qualidade, às vezes até o preço mais acessível do que de uma loja, então a tendência é buscar essa questão de preço. Pra mim, o importante não é só a qualidade do produto até porque não quero usar o produto para o resto de minha vida, eu quero adquirir um produto que tenha uma boa durabilidade e que o preço seja acessível. [Respondente (3)]

Depende. Às vezes uma amiga indica porque eu gostei da peça dela. Ainda existe a questão do "boca a boca", é uma propaganda muito forte. [Respondente (17)]

Isso. A pessoa comprou e gostou, já indica. Até a questão de se você não pode comprar o produto no momento, mas a pessoa faz com que você adquira dando melhor forma de pagamento. [Respondente (28)]

Os resultados mostram que o "boca a boca" ainda é muito contundente, mesmo a internet sendo mais utilizada. Sobressai da fala dos entrevistados que o conhecimento da qualidade do produto faz com que a indicação seja uma forma útil na hora da aquisição.

\subsubsection{Subcategoria: grau de satisfação}

A análise dessa subcategoria tem o fito de compreender o grau de satisfação das entrevistadas que compram no mercado informal, ou seja, as chamadas "sacoleiras". Para tanto, o seguinte questionamento foi realizado: "Você, como cliente, fica satisfeita em comprar de uma 'sacoleira'?’.

As observações das respondentes convergem para a confirmação do êxito, o que pode ser visto na sequência:

Revista Gestão e Secretariado (GeSec), São Paulo, SP, v. 12, n. 3, set./dez., 2021, p. 64-88. 
Sim. Elas vendem da mesma forma de quem tem a loja física, a única coisa que elas às vezes não têm é a divulgação do produto, eu acho que é onde elas perdem muito em relação à venda. [Respondente (3)]

Sou muito de comprar da mesma pessoa. Tipo se sempre ela traz algo que eu goste eu sempre vou procurar ela, pois eu sei que naquele lugar vou encontrar a peça que quero. [Respondente (12)]

Depende. Eu não deixo de comprar a uma pessoa na informalidade para comprar na loja, pois a loja hoje não é uma concorrente dessa pessoa, já a internet é. Na loja os preços são mais caros, o atendimento não é tão legal e as coisas não são tão personalizadas, diferentes. A pessoa da informalidade já conhece seu gosto, já te apresenta as peças que sabe que você vai gostar. [Respondente (20)]

As falas acima realçam a satisfação de comprar em "sacoleiras", mesmo muitas relatando que não são fiéis somente a uma. Geralmente, acontece de a "sacoleira" já saber o interesse de cada cliente, conseguindo deixá-la realizada na compra.

Assim, ainda com o intuito de corroborar e validar as presunções, realizou-se, com suporte do software NVivo ${ }^{\circledR}$, uma análise com base nas 30 palavras-chave que apareciam com maior frequência no discurso dos entrevistados para esse "nó".

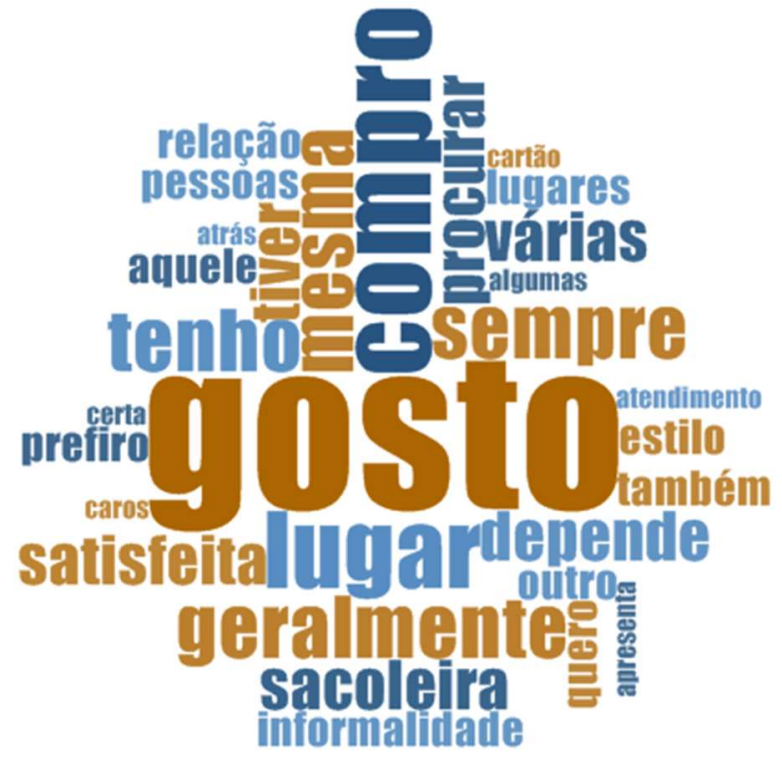

Figura 5. Nuvem de palavras da subcategoria "Grau de satisfação" Fonte: Elaborada pelos autores via NVIVO® (2018)

A execução da consulta e da análise dessas informações confirma o entendimento de Trim e Lee (2008) ao argumentar que, com o objetivo de conduzir a um melhor mapeamento das necessidades dos clientes, as organizações precisam responder rapidamente às 
transformações que envolvam produtos/serviços, preços, relacionamentos e tendências de mercado.

\subsection{Resultado ligado à "inteligência competitiva"}

A última categoria de análise apresenta a inteligência competitiva como forma de agregar valor no mercado informal, sendo composta por duas subcategorias: "Processo de informação" e "Tomada de decisão".

\subsubsection{Subcategoria: processo de informação}

Com a subcategoria "processo de informação", busca-se identificar alternativas para se obter a informação correta. Conforme já relatado por Prescott e Miller (2002), as informações, quando analisadas, transformam-se em inteligência. Para tanto, foi questionado aos entrevistados o seguinte: "O fato de você utilizar a informação prospectiva para compra de um produto faz você se considerar uma pessoa que toma boas decisões?".

Diante disso, eis algumas das percepções pertinentes ao questionado:

Sim. Porque hoje em dia temos uma oferta de preço muito variável. Se você for numa loja a questão de imposto tudo é mais caro. Então você procurando esse outro tipo de mercado você já sabe que vai ser mais barato, vai ter um acesso com relação à divisão. [Respondente (17)]

Sim. Até pela quantidade de informação que se chega para gente. Tem muita gente vendendo nas redes sociais. [Respondente (27)]

Talvez sim. Quando se tem uma informação, porque você conhece a informação boa e a informação ruim, quando alguém diz só para te agradar 'vá comprar em fulano que é mais barato'. E quando você tem uma informação boa, de qualidade fica satisfeito com as informações e vale a pena você adquirir o produto. [Respondente (30)]

Pode-se inferir dos trechos que, hoje em dia, devido a gama de informações, as pessoas procuram pensar mais no momento da compra, como relatam as entrevistadas $(17,27$ e 30$)$, visando melhor preço e qualidade.

Para complementar esse entendimento, a partir da transcrição das entrevistas, realizouse uma busca na árvore de palavras extraídas do $N V i v o ® ~ 11$. A árvore de palavras reúne frases e expressões das entrevistadas, com o objetivo de codificar as ligações mais próximas à subcategoria "Processo de informação", conforme visualizado na Figura 6. 


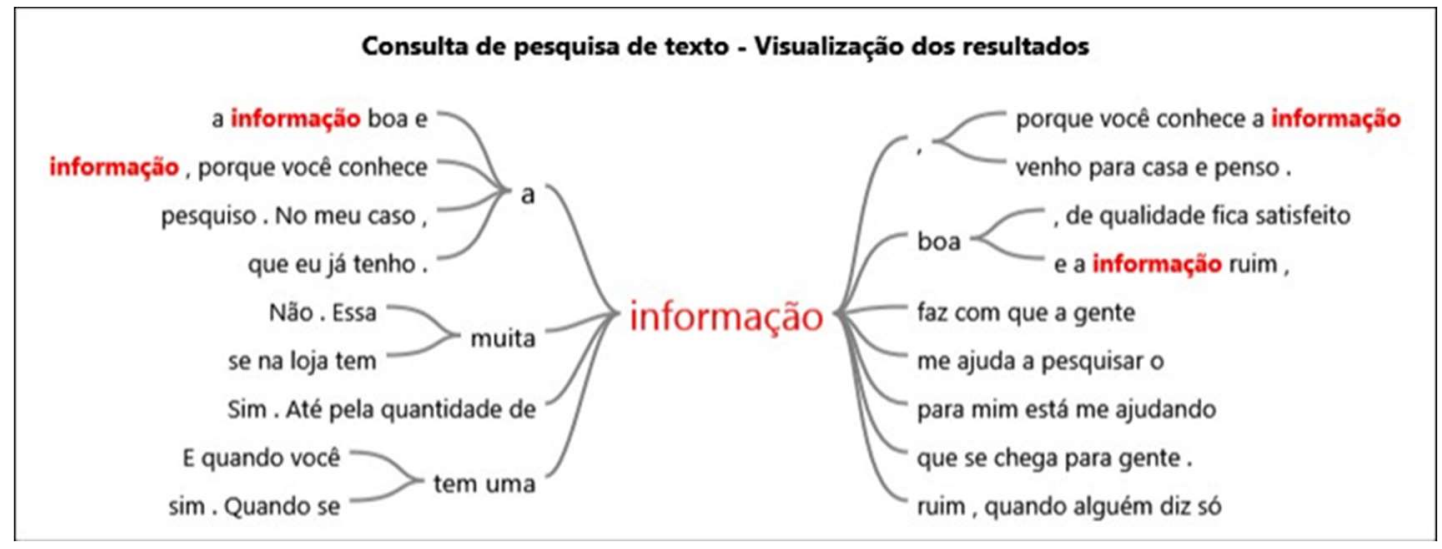

Figura 6. Árvore de palavras

Fonte: Resultados da Pesquisa (2018)

Sendo assim, identificou-se que a busca pela informação facilita o momento decisório. Assim, o processo de informação visa selecionar a quantidade de informação e as melhores, de modo a influenciar a tomada de decisão correta. Além disso, são inúmeros os propósitos de se obter e utilizar as informações, entre os quais: ajudar a pesquisar, mudar a forma de pensar, garantir qualidade e satisfação.

\subsubsection{Subcategoria: tomada de decisão}

Ao investigar o último "nó", "Tomada de decisão", a pesquisa procurou descobrir, entre as entrevistadas, de que maneira costumam saber as informações necessárias para a tomada de decisão. Sabe-se que hoje em dia todo mundo tem a facilidade de informação através das redes sociais. Assim, realizou-se o seguinte questionamento: "Você costuma usar as redes sociais para ficar por dentro das novidades? Quais?", auferindo-se as seguintes considerações:

Sim, principalmente o Instagram, o Facebook quase não uso. [Respondente (1)]

Sim. Instagram, Facebook, ou até mesmo pesquisa no Google que eu às vezes vejo uma blusa e vou procurar a marca, quem vende esse tipo de roupa. [Respondente (3)]

Sim. Instagram o que mais uso. E vejo alguma coisa em grupo de WhatsApp. [Respondente (27)]

Ao observar os discursos acima, com o suporte do software NVivo®, através de uma análise com base nas 30 palavras-chave de maior frequência na fala das entrevistadas, foram excluídas expressões como "entro", "mesmo”, “deixei”, entre outras. Conforme apresentado na Figura 7. 


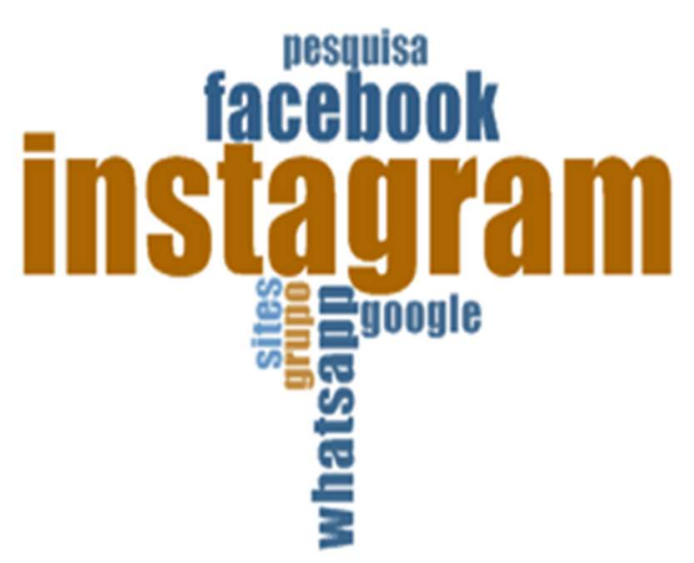

Figura 7. Árvore de palavras

Fonte: Resultados da Pesquisa (2018)

Conforme acima, a busca pela informação nas redes sociais é destaque entre as entrevistadas. Dentre as três primeiras, destacam-se o Instagram: dos 30 respondentes, 28 preferem usá-lo, em seguida, vem o Facebook e o WhatsApp fica na terceira opção.

Contudo, torna-se importante para o tomador de decisão enumerar todas as fontes de informação disponíveis para avaliar a perspectiva de cada fonte e definir os critérios incertos (Santos \& Gaspar, Schiozer, 2017). Nesse contexto, surge a prática da Inteligência Competitiva como modo de pensar e agir; um processo de coleta, análise e tratamento da informação, mesmo que intuitivamente pelo responsável da atividade, para uso antecipado frente aos concorrentes do segmento informal

\section{Considerações finais}

A última seção deste estudo tem a competência de expor o alcance do objetivo do trabalho. Os caminhos para chegar a essa temática está relacionado a atividade do pesquisador no setor informal do vestuário feminino. Dessa forma, foi elaborada perguntas para entrevista que pudessem obter respostas pertinentes para melhorias futuras. E diante disso, sugerir outras pessoas do setor a trabalhar com informação prospectiva como estratégica no mercado informal.

Organizar categorias e subcategorias temáticas proporcionou ao pesquisador segmentar o escopo do material coletado no campo e sistematizar a análise, de forma a apurar a qualidade das presunções, que são específicas à temática da análise de conteúdo proposta por Bardin (2011).

Com relação ao objetivo de estudo em conhecer a influência que a informação prospectiva exerce sobre o mercado informal do vestuário feminino, tem como questão que o

Revista Gestão e Secretariado (GeSec), São Paulo, SP, v. 12, n. 3, set./dez., 2021, p. 64-88. 
mercado informal, tratando-se de ser o escolhido pelos entrevistados, tem total relevância, sobretudo quando se trata de vestuário feminino. Assim, pode-se perceber pelos respondentes que, a informação prospectiva é considerada uma estratégia de ação no mercado informal de vestuário feminino. Sumariando, este trabalho permitiu observar que a atividade informal está crescendo cada vez mais e precisa-se adequar ações de influência e usá-las em momentos oportunos, para, assim, mostrar um novo cenário de atuação para o alcance do objetivo.

Proferido isso, a pesquisa teve como limitações o fato de não ser uma pesquisa quantitativa, como também, a abrangência da amostra. Além da dificuldade encontrada do pesquisador em realizar as entrevistas. Sugere-se realizar o estudo em outras regiões e utilizar uma amostra maior, pois o setor da informalidade tem apresentado grande crescimento, porém, pouco estudado. Assim, recomenda-se que novas investigações pertinentes a temática. Por fim, o estudo contribuiu muito para o pesquisador, pois o contado com cada entrevistado resultou em aprender mais das necessidades e desejos de cada um. Resultou-se, tanto de um crescimento profissional, quanto acadêmico.

\section{Referências}

Alonso-Almeida, M. D. M., Bremser, K.\& Llach, J. (2015). Proactive and reactive strategies deployed by restaurants in times of crisis: effects on capabilities, organization and competitive advantage. International Journal of Contemporary Hospitality Management, 27 (7), 1641-1661.

Andriotti, F. K., Freitas, H. \& Muniz, J. R. (2008). Informação informal e a monitoração do ambiente organizacional: reflexões e sugestões para a área de TI. In: Encontro da ANPAD, 32., 2008, Rio de Janeiro. Anais [...]. Rio de Janeiro: ANPAD.

Antunes, R. (2010). Os modos de ser da informalidade: rumo a uma nova era da precarização estrutural do trabalho? Configurações. Revista de sociologia, 7, 155-166.

Bauman, Z. (2001). Modernidade Líquida. Rio de Janeiro: Jorge Zahar Editor Ltda.

Bardin, L. (2011). Análise de conteúdo. São Paulo: Edições 70.

Bezerra, C. O. (2016). Marketing digital e comércio eletrônico na gestão social: estratégias para revitalizar as identidades e fazeres artesanais-o Website "Artesão Digital".

Calazans, A. T. S. (2008). Qualidade da informação: conceitos e aplicações. TransInformação, 20(1), 29-45. 
Casimiro, A. H. T., \& Araújo, W. J. (2020). Cenários prospectivos. RDBCI: Revista Digital de Biblioteconomia e Ciência da Informação, 18, e020003-e020003.

Corrar, L. J.; Paulo, E.; Dias Filho, J. M. (2009). Análise Multivariada: para os cursos de Administração, Ciências Contábeis e Economia. São Paulo: Atlas.

Coughlin, C., Lyons, K. E.\& Ghetti, S. (2014). Remembering the past to envision the future in middle childhood: developmental linkages between prospection and episodic memory. Cognitive Development, 30, 96-110.

Chang, C. H. (2015). Proactive and reactive corporate social responsibility: antecedent and consequence. Management Decision, 53 (2), 451-468.

Creswell, J. W. (2010). Projeto de pesquisa métodos qualitativo, quantitativo e misto. Tradução Magda Lopes. 3. ed. Porto Alegre: Artmed.

da Silva, D. P. A., Figueiredo Filho, D. B., \& da Silva, A. H. (2015). O poderoso NVivo: uma introdução a partir da análise de conteúdo. Revista política hoje, 24(2), 119-134.

Davison, R. M., Ou, C. X. J. \& Martinsons, M. G. (2013). Information technology to support informal knowledge sharing. Information Systems Journal, 23 (1), 89-109.

Ding, Y. (2017). Modelling continued use of information systems from a forward-looking perspective: antecedents and consequences of hope and anticipated regret. Information \& Management, 5 (4), 461-471.

Drucker, P. F. (1988). The coming of the new organization. Harvard Business Review, 66, 4553.

Eidizadeh, R., Salehzadeh, R.\& Esfahani, A. C. (2017). Analysing the role of business intelligence, knowledge sharing and organizational innovation on gaining competitive advantage. Journal of Workplace Learning, 29 (4), p. 250-267.

Farrow, D.; Reid, M. (2012). O contributo da informação de probabilidade situacional para a habilidade antecipatória. Journal of Science and Medicine in Sport, 15(4), 368-373.

Flick, U. (2009). Introdução à pesquisa qualitative. (3. ed). Porto Alegre: Artmed.

Fuller, T. (2016). Anxious relationships: the unmarked futures for post-normal scenarios in anticipatory systems. Technological Forecasting and Social Change, 124, 41-50.

Freitas, H.\& Janissek-Muniz, R. (2006). Uma proposta de plataforma para Inteligência Estratégica. In: Congresso Ibero-Americano de Gestão do Conhecimento e Inteligência Competitiva, 1., 2006, Curitiba. Anais [...]. Curitiba: GeCIC.

Gatsoris, L. (2012). Competitive intelligence in Greek furniture retailing: a qualitative approach. EuroMed Journal of Business, 7 (3), 224-242. 
Gallin, D. (2001). Propositions on trade unions and informal employment in times of globalization. Antipode, 33 (3), 531-549.

Guston, D. H. (2014). Understanding “anticipatory governance”. Social Studies of Science, $44(2), 218-242$.

Hirata, H. S. (2004). O universo do trabalho e da cidadania das mulheres: um olhar do feminismo e do sindicalismo. Reconfiguração das relações de gênero no trabalho. São Paulo: CUT, 2004. 13-20.

Kaye, D. (1995). The importance of information. Management Decision, 33(5), 5-12.

Kestenbaum, N. (2008). Obrigado pela informação que você não me deu! Rio de Janeiro: Elsevier.

Lage, M. C. (2011). Utilização do software NVivo em pesquisa qualitativa: uma experiência em EaD. ETD-Educação Temática Digital, 12(esp.), 198-226.

Leone, E. T.; Baltar, P. (2008). A mulher na recuperação recente do mercado de trabalho brasileiro. Revista Brasileira de Estudos de População, 25 (2), 233-249.

Levet, J. L. (2001). L'intelligence économique: mode de pensée, mode d'action. Paris: Economica, 2001

Leavy, S. (2007). Análise prospectiva dos agronegócios no município de Pergamino, Buenos Aires, Argentina. 2007. 95 f. Dissertação (Mestrado) - Programa de Pós-graduação em Agronegócios, Centro de Estudos e Pesquisas em Agronegócios, Universidade Federal do Rio Grande do Sul, Porto Alegre.

Lima, J. L. O., \& Manini, M. P. (2017). Metodologia para análise de conteúdo qualitativa integrada à técnica de mapas mentais com o uso dos softwares Nvivo e Freemind. Informação \& Informação, 21(3), 63-100.

Melo, M. A. N.; Medeiros, D. D. (2007). A model for analyzing the competitive strategy of health plan insurers using a system of competitive intelligence. The TQM Magazine, 19 (3), 206-216.

Menezes, W. F.; Dedecca, C. S. (2014). A informalidade no mercado de trabalho brasileiro: rendimentos e principais características. Revista Nexos Econômicos, 6 (2), 11-42.

Mozzato, A. R.; Grzybovski, D. (2011). Análise de conteúdo: ampliando e aprofundando a reflexão sobre a técnica de análise de dados qualitativos no campo da administração. Revista de Administração Contemporânea, 15(4), 766-775.

Natividade, D. R. da. (2009). Empreendedorismo feminino no Brasil: políticas públicas sob análise. Revista de Administração Pública, 43 (1), 231-256. 
Potrich, A. C. G.; Ruppenthal, J. E. (2013). Empreendedorismo na informalidade: um estudo de caso no Shopping Independência de Santa Maria/RS. Revista GEPROS, 9 (3), 145.

Porter, M. E.; Millar, V. E. (1985). How information gives you competitive advantage. Harvard Business Review, 63(4), 149-160.

PHELAN, S. T. (2002). Fads and fashions: the price women pay. Primary Care Update for $O B / G Y N S, 9$ (4), 138-143.

Prates, I., \& Barbosa, R. J. (2020). The Impact of COVID-19 in Brazil: Labour Market and Social Protection Responses. The Indian Journal of Labour Economics, 63(1), 31-35.

Prescott, J. F.; Miller, S. H. (2002). Proven strategies in competitive intelligence: lessons from the trenches. Hoboken, USA: John Wiley \& Sons.

Prodanov, C. C.; Freitas, E. C. de. (2013). Metodologia do trabalho científico: métodos e técnicas da pesquisa e do trabalho acadêmico. 2. ed. Novo Hamburgo: Feevale.

Rosen, R. (2012). Anticipatory systems: philosophical, mathematical, and methodological foundations. 2nd. ed. In: International Federation for Systems Research International Series on Systems Science and Engineering, 1, 3, 13-370.

Santos, S. M. G.; Gaspar, A. T. F. S.; Schiozer, D. J. (2017). Value of information in reservoir development projects: Technical indicators to prioritize uncertainties and information sources. Journal of Petroleum Science and Engineering, 157, 1179-1191.

Satur, R. V.; Paiva, S. B.; Duarte, E. N. (2017). Informação imperfeita e seu impacto nas estratégias empresariais. Brazilian Journal of Information Science: Research Trends, 11 (2).

Schenatto, F. J. A.; Polacinski, E.; De Abreu, A. F.; De Abreu, P. F. (2011). Análise crítica dos estudos do futuro: uma abordagem a partir do resgate histórico e conceitual do tema. Gestão \& Produção, 739-754.

Tapinos, E.; Pyper, N. (2018). Forward looking analysis: Investigating how individuals "do" foresight and make sense of the future. Technological Forecasting and Social Change, 126, 292-302.

Torres, D. F. U. (2015). Análise prospectiva para o setor atacadista de flores e plantas ornamentais no Brasil e suas tecnologias da informação e comunicação. 2015. Dissertação (Mestrado em Agronegócios) - Universidade Federal do Rio Grande do Sul, Porto Alegre.

Trim, P. R. J.; Lee, Y. I. The role of marketing intelligence officers in strategy formulation and implementation. Handbook of business strategy, 7 (1), 125-130. 
Villerd, S. M.; Hardill, I. (2010). Paris and fashion: reflections on the role of the Parisian fashion industry in the cultural economy. International Journal of Sociology and Social Policy, 30(9-10), 461-471.

Wright, S.; Calof, J. L. (2006). The quest for competitive, business and marketing intelligence: a country comparison of current practices. European Journal of Marketing, 40(5-6), 453465 .

Williams, C. C.; Martinez-Perez, A. (2014). Why do consumers purchase goods and services in the informal economy? Journal of Business Research, 67(5), 802-806.

Submetido em: 27.11 .2020

Aceito em: $\quad 31.05 .2021$ 